\title{
PAISAGEM, ARQUEOLOGIA E OS LUGARES TRANSFORMADOS: A ALAMEDA BRÜSTLEIN EM JOINVILLE (SANTA CATARINA)
}

\author{
Anna Kelly Krassota ${ }^{1}$ \\ Dione da Rocha Bandeira ${ }^{2}$ \\ Fernanda Mara Borba ${ }^{3}$ \\ Graciele Tules de Almeida ${ }^{4}$
}

\section{RESUMO}

Esse artigo trata sobre a pesquisa arqueológica desenvolvida na Alameda Brüstlein (Joinville, Santa Catarina), um espaço construído para servir como jardim de entrada da Maison, residência relacionada ao Príncipe e a Princesa da antiga Colônia Dona Francisca. Atualmente a Maison abriga o Museu Nacional de Imigração e Colonização e, junto à Alameda Brüstlein, compõe a paisagem cultural urbana do centro da cidade, formando um importante conjunto arquitetônico e paisagístico. Pensando na preservação e proteção da história da cidade e em seu referencial simbólico, a Alameda foi tombada como Patrimônio Histórico e Artístico Nacional (Decreto Municipal n. $12.276,2005)$ e, por tal razão, passou por ações de salvamento arqueológico no contexto de sua requalificação. Nesse estudo, adotou-se a perspectiva da arqueologia histórica e da paisagem, contribuindo na reflexão sobre os jardins históricos como lugares pensados, vividos e transformados, acrescentando alguns questionamentos sobre o valor simbólico, ideológico e representativo desses espaços construídos. Assim, partindo da identificação desse passado, o patrimônio passa a ser uma janela da memória incrustada nos centros urbanos, no meio rural ou na paisagem cultural, podendo ser acessada a qualquer momento que o indivíduo assim desejar.

Palavras-chave: Alameda Brüstlein, Arqueologia Histórica, Joinville, Paisagem.

\footnotetext{
${ }^{1}$ Pesquisadora na Universidade da Região de Joinville (Univille). Graduada em Ciências Biológicas, especialista em Economia e Meio Ambiente e mestranda em Patrimônio Cultural e Sociedade. E-mail: annakelly_@hotmail.com.

${ }^{2}$ Professora na Universidade da Região de Joinville (Univille) e Arqueóloga no Museu Arqueológico de Sambaqui de Joinville (Masj). Graduada em Ciências Biológicas, mestre em Antropologia e Doutora em História. E-mail: dione.rbandeira@gmail.com.

${ }^{3}$ Pesquisadora na Universidade da Região de Joinville (Univille). Graduada em História, especialista em Arqueologia e mestre em Patrimônio Cultural e Sociedade. E-mail: fernanda.soet@gmail.com.

${ }^{4}$ Pesquisadora na Universidade da Região de Joinville (Univille). Graduada em História, especialista em Arqueologia e mestranda em Patrimônio Cultural e Sociedade. E-mail: gtametal@gmail.com.
} 


\section{INTRODUÇÃO}

Este artigo apresenta os resultados de um estudo arqueológico desenvolvido na Alameda Brüstlein, uma rua situada na área central da cidade de Joinville (Figura 1), dentro das atividades da sua requalificação, reunindo informações sobre as histórias construídas nesse espaço com as produzidas nesta pesquisa. Os trabalhos foram baseados na análise de antigas propriedades como habitações e estabelecimentos comerciais do entorno, coleções arqueológicas, documentos oficiais, jornais, mapas e fotografias e depoimentos orais, em grande parte com uma baliza temporal situada entre a segunda metade do século XIX e o XX. A confluência de diferentes fontes ampliou os estudos e apresentou mais dados sobre as moradias e aos objetos cotidianos dos joinvilenses, elaborando algumas interpretações a respeito dos espaços e vestígios associados à Alameda Brüstlein. Para esse artigo, a reflexão terá como base a iconografia e na estratigrafia registrada durante a pesquisa arqueológica.

Figura 1. Localização de Joinville (em destaque) e demais municípios integrantes da região Norte-Nordeste do Estado de Santa Catarina

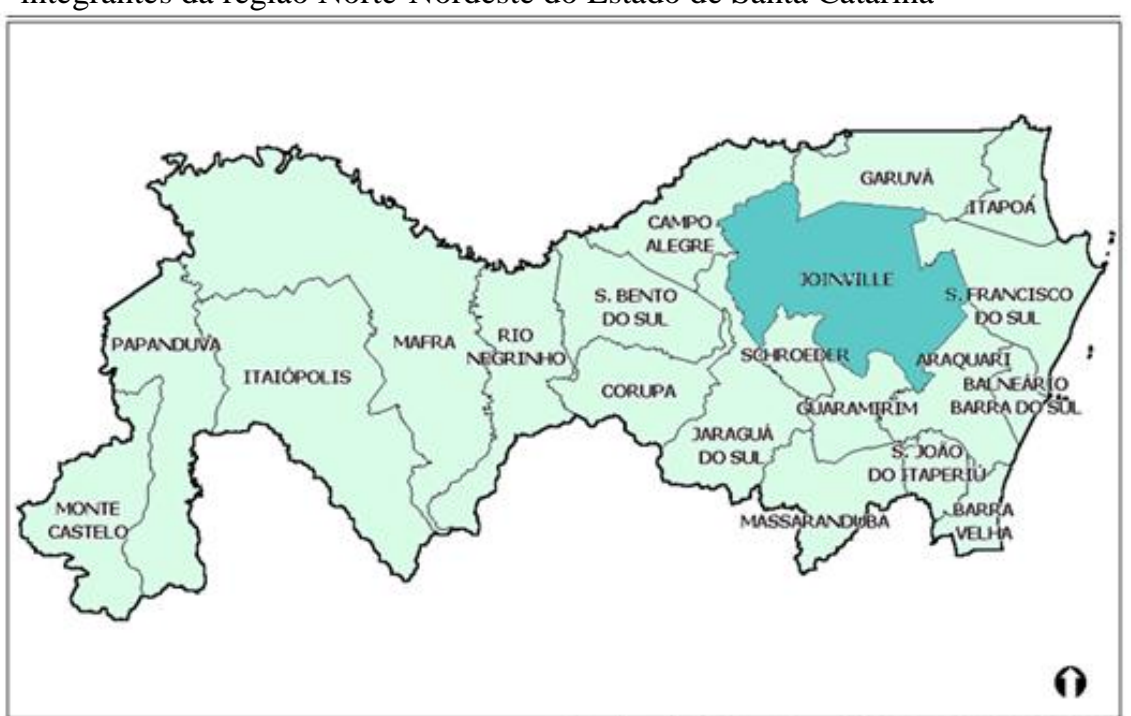

Fonte: Observatório de Políticas Urbanas e Gestão Municipal (IPPUR/UFRJ-FASE, 2003).

A história da Alameda Brüstlein se mistura com o início do povoamento da própria cidade, marcado na segunda metade do século XIX com a vinda de alemães, suíços, noruegueses e dinamarqueses, no decorrer do processo de colonização do local. O empreendimento foi promovido pela Sociedade Colonizadora de Hamburgo em contrato com o Príncipe de Joinville, proprietário de terras na região, dando origem, em 
9 de março de 1851, a Colônia Dona Francisca, hoje cidade de Joinville (FICKER, 1965). Com o estabelecimento do empreendimento, organizado por Frederico Bruestlein, representante do príncipe no Brasil no período, inicia-se a construção da nova sede para o Domaine Dona Francisca, com a apresentação da planta da nova residência à Adolph Haltenhoff, subdelegado e proprietário da olaria que forneceria os tijolos e as telhas para a construção, iniciada em 1867. Três anos depois, de acordo com o historiador Ficker (1965), a Maison de Joinville, como ficou conhecida na época, estava praticamente concluída. As palmeiras que completam o conjunto paisagístico da Alameda Brüstlein foram semeadas em 1867 e replantadas em 1873, pelo então diretor da Colônia Louis Niemeyer que, ao retornar de uma viagem ao Rio de Janeiro, trouxe consigo sementes das palmeiras imperiais (Oreodoxa oleracea) do Jardim Botânico (FICKER, 1965). Após serem germinadas e, contando com aproximadamente um metro de altura, foram transplantadas para o atual local, entre os anos de 1871 e 1873 (FICKER, 1965).

Ainda no século XIX, com o desenvolvimento urbano da Colônia, algumas ruas foram alargadas e novas vias foram abertas, especialmente as que ainda compõem o entorno do Museu Nacional de Imigração e Colonização (MNIC) e a Alameda, como Rua do Príncipe e a Rua Rio Branco. Neste processo, quatro palmeiras foram sacrificadas, duas em cada extremidade da Alameda, restando 52 das palmeiras iniciais. No século seguinte, novamente o espaço sofre modificações. Em 1973, o Prefeito Pedro Ivo Campos transforma a Rua das Palmeiras, como também é conhecida, anteriormente pavimentada e com tráfego de veículos, em Boulevard, a partir do projeto do artista plástico Juarez Machado. Junto ao projeto urbanístico do local, houve a transferência do busto da Princesa Dona Francisca, criado pelo escultor Fritz Alt em comemoração aos 75 anos de Joinville, da Praça Lauro Müller para a Alameda. Considerando a importância do espaço para a cidade, em 9 de março de 2005, em comemoração ao aniversário de 154 anos de Joinville, sob Decreto Municipal (n. 12.276), foi homologado o tombamento da Rua das Palmeiras com o intuito de (JOINVILLE, 2005):

Preservar e proteger a história do Município de Joinville, [...] [pois] a Alameda Brüstlein é um Patrimônio do Município que testemunha a sua história desde os primórdios da sua colonização pelos imigrantes; [...] em seu traçado original, integra de forma singular e está associada indissoluvelmente ao acesso do Museu Nacional de Imigração e Colonização, criado pela União e tombado como Patrimônio Histórico e Artístico Nacional; [...] [ela] confere 
ao paisagismo urbano de Joinville características inconfundíveis e é, há mais de um século, referência e símbolo da cidade.

Por fim, e mais recentemente, uma última modificação abarcou o patrimônio em tela e, igualmente promovida pelo poder público municipal, houve em 2012 a sua requalificação, transformando o Boulevard em uma rua novamente, com passagem de carros nas laterais e pedestres em sua área central. Considerando, porém, o tombamento do espaço, as ações da revitalização da Alameda Brüstlein contemplou, entre diversas atividades, uma pesquisa de monitoramento e salvamento arqueológico, sob a coordenação do Museu Arqueológico de Sambaqui de Joinville (MASJ) e participação de técnicos da Coordenadoria do Patrimônio Histórico de Joinville (CPC), do Centro de Preservação de Bens Culturais (CPBC) e do MNIC.

\section{A ARQUEOLOGIA NA ALAMEDA BRÜSTLEIN}

Por se tratar de um espaço público tombado pelo município, todas as etapas das obras executadas no Projeto de Revitalização da Alameda Brüstlein foram monitoradas e alguns locais sofreram o salvamento arqueológico, conforme solicitação da Comissão de Patrimônio Histórico, Arqueológico, Artístico e Natural do Município de Joinville (Comphaan). Considerando-se a legislação de proteção ao patrimônio arqueológico e os interesses científicos e sociais, a intervenção arqueológica pôde contribuir com informações relevantes sobre este importante bem cultural do município de Joinville. E mesmo tratando-se de pequenas intervenções, as ações executadas permitiram reflexões sobre as relações da população, no decorrer dos anos, com um espaço social central. Nesse sentido, Yustos acredita que:

\footnotetext{
ha resultado ser muy útil para explicar el passado de la humanidad gracias a sua capacidad de reconocimiento y evaluación de las dinâmicas e interdependências que los grupos humanos mantienen com las dimensiones físicas, sensoriales y socioculturales del espacio que habitan. Su facultad de aglutinar diferentes escenarios de acción habilita a esta perspectiva para la difícil tarea de resolver los principales problemas a los que enfrenta la arqueologia: la variabilidad espacio/temporal del registro y las dinâmicas de cambio cultural (YUSTOS, 2010, p. 146).
}

A incorporação da paisagem como objetivo de análise pela arqueologia resulta da convicção de que, por se tratar de um elemento da cultura material passível de ser analisado como um artefato, se enquadra em seu campo de investigação. A perspectiva 
que concebe as paisagens como artefato lida, intrinsecamente, com a ambiguidade de sua própria natureza, ou seja, com seu caráter passivo (como produto de relações sociais) e ativo (como vetor de relações sociais) (MENEZES, 1983).

A Alameda Brüstlein já passou por transformações ao longo de sua história - no princípio quando foram plantadas as palmeiras, era apenas um caminho de acesso à casa da administração, com o tempo passou a função de rua sem pavimentação e depois, por muitos anos, após ser calçada em paralelepípedo, recebeu o tráfego urbano da cidade. Apenas no início da década de 1970, sob o título de Boulevard, sua paisagem foi modificada possibilitando apenas o tráfego de pedestres, ficando o acesso de carros possível apenas em suas as laterais. Na mesma época, a comissão do MNIC sugeriu que o centro da Alameda permanecesse como passagem aos pedestres, para que ela não perdesse a sua finalidade de servir de acesso ao museu. Nesse sentido, é necessário ressaltar essa ligação uma vez que a Alameda está historicamente conectada e simbolicamente referida ao MNIC, sendo identificada como um espaço dinâmico que articula diferentes sociabilidades e apropriações, tanto dos joinvilenses, quanto dos visitantes do museu e da cidade.

Mesmo sendo palco de diversas territorialidades e um espaço reivindicado por vários grupos da cidade, como um local de apego, circulação e memória, infelizmente, segundo moradores do entorno e transeuntes, o fechamento da rua e a falta de incentivo à realização de atividades diversas no espaço público, fez com que a Alameda ficasse sem o movimento adequado. Isso, de acordo com os informantes, contribui para uma situação de insegurança no local, fazendo com que muitas pessoas que costumavam utilizar a Alameda como passagem ou para passeio, deixassem de frequentar o espaço, pela descaracterização de sua ideia primária, imprimindo em seu espaço diferentes feições e cenários da experiência social. Lourenço enfatiza que

\footnotetext{
as cidades industrializadas não inventaram o espaço público, mas sua versão moderna e contemporânea. Estas cidades, como Joinville, não estão destruindo o espaço público, mas instaurando a privatização, o enclausuramento e instrumentos de distanciamento que criam uma esfera fragmentada, de segregação social a partir da negação da importância dos bens patrimoniais tombados pela União, Estado e Município, para a memória coletiva de seus habitantes (LOURENÇO, 2011, p. 24).
}

Portanto, conclui o autor, são imprescindíveis as realizações por parte do poder público, de ações que visem garantir a qualificação e o acesso aos bens culturais e aos 
espaços de sociabilidade. Tendo como referências os ideais de igualdade e de direitos coletivos, assim como o direito à memória.

\section{AS CONTRIBUIÇÕES DA ARQUEOLOGIA HISTÓRICA E DA PAISAGEM}

A arqueologia se constitui como uma ciência que estuda as sociedades humanas por meio de aspectos culturais consolidados na materialidade e tem sua importância ao discutir os usos e significados atribuídos aos artefatos em períodos e espaços distintos pela sociedade. A partir dos vestígios e as diferentes áreas de atuação, a arqueologia permite um olhar crítico ao passo que fornece estudos que ultrapassam a simples coleta de artefatos, possibilitando interpretações e a valorização dos bens sociais e o patrimônio material das comunidades (ORSER, 1992). Abrangendo o período colonial (escravista) e posterior (capitalista), a arqueologia histórica ainda pode ser vista como

\footnotetext{
la arqueología que se ocupa de todas aquellas sociedades sobre las que existen fuentes escritas, incluyendo aquellas sociedades iletradas sobre las que sí escribieron. Algunos autores definen el campo de forma más estrecha, como la arqueología que trata del estúdio de los últimos 500 años, centrándose especialmente en la expansion colonial europea y su impacto (HILLS, 2008, p. 100-101).
}

Considera-se fundamental essa abordagem, pois "is particularly fitted to the study of class divisions and exploitation, providing direct access to the everyday lives of all members of society, not only elites, but also peasants, merchants, slaves and poor people" (FUNARI, 1999, p. 57). Com a ampliação das suas ações, a arqueologia histórica procura identificar espaços, estruturas e objetos pertencentes aos diversos grupos sociais para compreender suas transformações e seus conflitos. Ao contribuir com outras leituras possíveis dessa história, tal linha de pesquisa recorre a vozes abafadas, práticas esquecidas e culturas reprimidas (ORSER, 1992, p. 11), indicando uma realidade um pouco diferente da que foi passada pela oficialidade, permitindo rever algumas interpretações do passado.

Iniciada nos Estados Unidos, a arqueologia histórica passou a ser alvo de investigação no Brasil a partir da década de 1960, abarcando diferentes fontes como os artefatos, estruturas, documentos escritos, informações orais e iconográficas e tem cada vez mais, ganhado espaço em diferentes âmbitos, públicos e privados, acadêmicos e informais. 
Dentro dessa perspectiva e colaborando nesses estudos, se insere a arqueologia da paisagem que discute as interações entre os seres humanos e o ambiente ao qual vivem e percorrem, estabelecendo percepções e conceitos através de processos cognitivos e consequentemente culturais, desta forma, a paisagem passa a ser vista como uma construção social. Tem como método a compreensão dos mecanismos de interação entre os indivíduos e a natureza, visando o entendimento dos sítios de forma ampla, com base na discussão sobre a cultura material, mas principalmente o entorno do sítio e também no espaço alterado socialmente e seu conteúdo cultural, caracterizado como a paisagem.

A paisagem, segundo a Geografia, pode ser diferenciada em duas categorias: a natural e a cultural. A paisagem natural abrange o espaço e seus elementos combinados como rios, lagos, vegetação, solo e atributos de região, enquanto a paisagem cultural inclui o espaço alterado, transformado em lugar carregado de sentido e apego, através das modificações feitas pelo homem, como os espaços urbanos e rurais (SCHIER, 2003). Utilizado ao lomgo do tempo por diversas disciplinas, é no início do século XX que o conceito de paisagem passa a ser atribuído ao resultado da interação entre indivíduos, a cultura e o meio ambiente. Conforme Sauer, "el paisaje cultural es creado por un grupo cultural a partir de un paisaje natural. La cultura es el agente, el área natural es el medio, el paisaje cultural es el resultado" (SAUER, 1925, p. 46). Assim, a paisagem alavancou diversas discussões a respeito dos espaços transformados a partir da relação dialética entre os indivíduos e a natureza.

Primeiramente, a Arqueologia da Paisagem tem sua origem na década de 1960, no desabrochar da Nova Arqueologia, que surge com o intuito de contrapor o método histórico-culturalista utilizado na arqueologia até então (VILLAESCUSA, 2006), tendo como pressupostos epistemológicos o neopositivismo, a Ecologia Cultural e a Teoria Geral dos Sistemas, que vão influenciar profundamente o fazer da arqueologia naquele momento. Inicialmente tinha como objetivo analisar sistematicamente as relações humanas e os espaços, a partir da distribuição dos materiais e padrões de assentamentos para compreender as estratégias de mobilidade e ocupação do meio ambiente pelos grupos do passado, bem como, perceber as interações entre indivíduos e o meio onde se estabelecem a partir da Ecologia Cultural, contribuindo para a percepção das alterações físicas do espaço, relacionando os resultados a questões econômicas e adaptativas 
(YUSTOS, 2010). Nesse sentido, nas décadas seguintes surgiram várias críticas ao cientificismo exagerado da Nova Arqueologia, a partir do movimento pós-processual, que defendia novos olhares para o contexto arqueológico extrapolando as análises estatísticas e dando ênfase ao processo transformador da mente humana. A partir desse momento, a Arqueologia da Paisagem ganhou novas abordagens, contribuindo para compreensão de questões além do processo de produção da cultura material, aproximando-se cada vez mais de questões relacionadas à percepção e cognição (LINKE, 2008).

Ao adentrar o contexto da inter-relação homem, tempo, espaço e meio a partir da pesquisa, passa-se a entender a paisagem como resultado dessa relação, como reflexo de suas ações, mas também do seu engajamento com o mundo e como continuidade da sua realidade cultural (INGOLD, 2000). A paisagem deixa de ser o pano de fundo das ações humanas e passa a ser ativa no que tange as relações sociais e culturais. Desta forma, compreende-se a paisagem como corporificação da relação homem, cultura e meio.

Assim, a Arqueologia da Paisagem propõem discutir, a partir do espaço moldado, as inter-relações entre sujeito, natureza e a cultural material de forma ativa, relacionando o natural e o social, bem como, estratégias, tecnologias, saberes e significados atribuídos, pois o espaço alterado pela ação humana transborda o meio físico que passa a ter sentido e significado, adquirindo status de lugar, isto é, "lugar de memória".

\section{A PAISAGEM DA ALAMEDA BRUSTLEIN: LUGARES TRANSFORMADOS}

Ao contemplar a paisagem da Alameda Brüstlein, pode-se perceber uma infinidade de relações e processos que se dão a partir da ação humana. Assim, ao olhar a paisagem construída, deve-se considerar as relações que permeiam a construção dessa paisagem e de que forma essas transformações podem contribuir para se entender a história desse lugar e como ocorreram naquele contexto. Segundo Silva (1997, p. 149)

a distinção entre paisagem física e paisagem cultural, como feita na história, e ainda prevalece na geografia, deve ceder espaço para uma nova visão, cuja ênfase recaia nos resultados da ação do homem sobre o meio ambiente. Devemos entender a natureza, nesta visão, não mais como um dado externo e imóvel, mas como produto de uma prolongada atividade humana. 
Ao se pensar a Alameda Brüstlein como resultado de uma relação intrínseca entre indivíduos e a natureza, é possível estabelecer uma topografia dos interesses e sentidos atribuídos à paisagem alterada, servindo de aporte para a compreensão de processos históricos e a reconstrução da memória social. Ao observar a natureza os indivíduos estabelecem noções de apego a partir da percepção que carregam do mundo e das intenções que estabelecem com o meio, pois "não existe um olhar virgem, espontâneo, inocente. O olhar não é somente o exercício de um sentido (a visão), ele é também a produção de sentido (significação)" (RONAI, 1976). Nessa relação, a paisagem revela-se misteriosa e intacta com toda a sua imensidão podendo causar um deslumbramento e excitação momentânea fruto desse primeiro contato. A descrição da paisagem encontrada às margem do Rio Cachoeira pelos primeiros colonos indicam esse "deslumbramento inicial” ao observá-la. Conforme Rodowicz-Oswiecimsky,

\begin{abstract}
só se pode afirmar, ser um espetáculo deslumbrante, no qual a palmácea coqueiro sobressai do conjunto, com sua coroa ao topo. Mostra-se o verde em todas as tonalidades, desde o bem escuro até o suave verde desmaiado, com as árvores imponentes a exibirem tudo aquilo e nos quais se enrolavam as mais variadas espécies de trepadeiras com suas flores, convidando a tomaram seus lugares os mais coloridos e belos pássaros que se possa imaginar, ao lado das mais lindas orquídeas, helicônias misturadas com verde amarelado dos ananás e de folhagens largas e coloridas. O emaranhado dos juncos e taquaras, como se fecham este santuário virgem com uma parede impenetrável que somente, à mão armada, o intruso consegue violar. Apreciando a maravilha dos diversos grupos de árvores, chega-se a conclusão de que nenhum jardineiro seria capaz de sorti-las melhor, e sem querer o espectador sente seus pensamentos elevarem-se ao Criador desta majestosa beleza! (RODOWICZ-OSWIECIMSKY, 1853, p. 29).
\end{abstract}

O contato seguinte com a paisagem local revela o nascimento da futura colônia com o derrubar das árvores e o ruído dos machados característico daquele momento, abrindo clareiras onde antes se encontrava a mata fechada. Conforme Avé-Lallemant (1858 apud GUEDES, 2005, p. 26) constatou:

o que se vê em Joinville está em começo. Canta o machado à esquerda e à direita e penetra no tronco das grandes árvores da mata. Um estalido ligeiro, quase imperceptível, adverte o diligente trabalhador. Mais um golpe e estrala o tronco e crepita forte e com violento ruído lentamente se precipita ao solo, de modo que o homem, se prudente, sempre tem tempo de recuar para não ser ferido pelo tronco que desaba. [...] Com um ruído crepitante desaba um pequena mata e onde antes havia escuras brenhas se forma uma perfeita clareira.

Os relatos também apontam para as dificuldades com o meio e a maneira pela qual os colonos encontraram para "tornar habitável" a paisagem hostil. Segundo 
Guedes, "a colônia estava assentada em um terreno de mangue, extremamente úmido e sujeita a enchentes constantes, [...] [dessa forma] o desmatamento e o aterramento eram necessários e, talvez, a única maneira de tornar habitável a maior parte das terras da princesa" (GUEDES, 2005, p. 16-25). Os primeiros anos da Colônia Dona Francisca se caracterizam pelo transformar incessante da paisagem, com a abertura de ruas e a limpeza de novos lotes a espera dos colonos que continuavam a imigrar. Quase vinte anos após a chegada dos primeiros imigrantes, a Colônia contava com várias ruas abertas e com algumas propriedades voltadas para a pequena produção agrícola, o que fomentou o crescimento da cidade naquele período (FICKER, 1965) (Figura 2).

Figura 2. Rua do Príncipe em 1866.

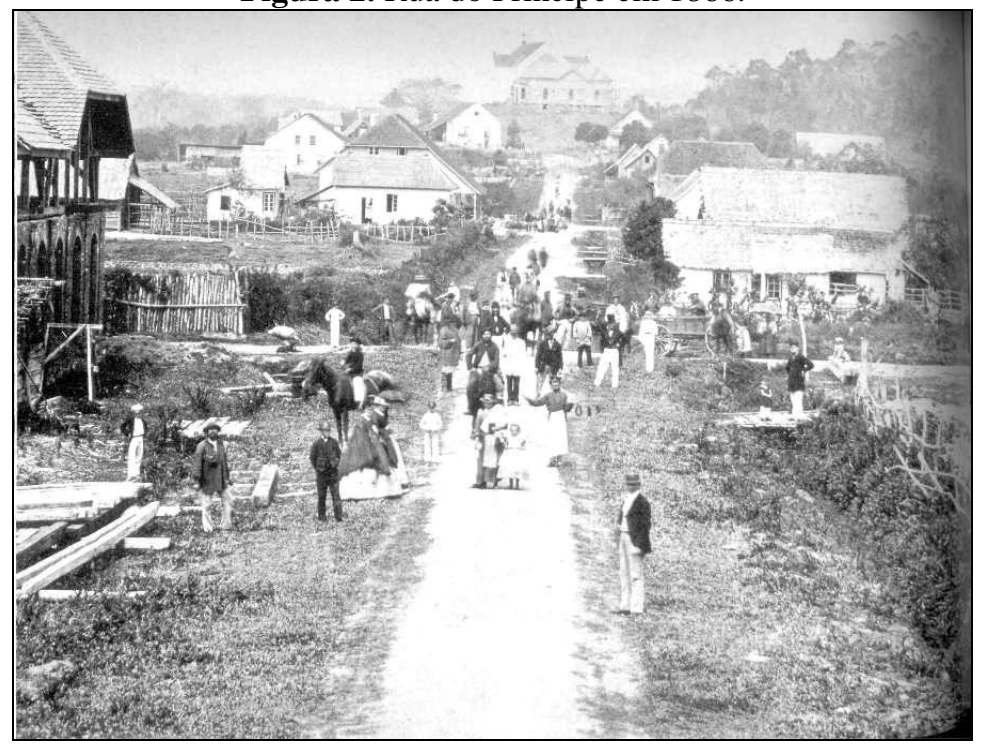

Fonte: AHJ (1866).

Nesse contexto, com o crescimento da Colônia e a necessidade de construção de uma nova sede para a administração, inicia a história da Alameda Brüstlein, com a solicitação do representante do príncipe, Brüstlein, ao então diretor da colônia, Louis Niemeyer, que trouxesse do Rio de Janeiro em 1867, as sementes das palmeiras imperiais (Oreodoxa oleracea) do Jardim botânico (FICKER, 1965). A escolha das palmeiras imperiais por certo refletia o gosto do Príncipe de Joinville, de Frederico Brüstlein e também do Príncipe Regente, D. João VI, que havia plantado uma muda da mesma espécie de palmácea trazida das Antilhas em 1809 (FICKER, 1965). As palmeiras imperiais como o próprio nome pode indicar apresentam-se de forma majestosa e suntuosa, abrindo alas com sua altíssima imponência para o Palácio dos 
Príncipes, sua inserção na paisagem não é mera coincidência do destino, mas simboliza um tempo de majestade, de realeza, de príncipes e princesas, configurando momentos que antecederam o fim da monarquia no Brasil.

As modificações nesse espaço podem ser percebidas a partir da estratigrafia registrada durante a pesquisa arqueológica (Figura 3). Inicialmente, tem-se o terreno original - delimitado pela linha na cor preta - que apresenta um solo argiloso bastante úmido no qual foram encontrados artefatos arqueológicos do período de ocupação mais antigo e, portanto, está abaixo dos aterros, indicando a presença de terrenos alagadiços. No segundo momento, tem-se a primeira camada de aterro - entre as linhas preta e vermelha - que poder ser resultante do processo de elaboração do caminho de acesso à casa de administração com o replantio das palmeiras imperiais em 1873 (Figura 3).

Figura 3. Estratigrafia da Alameda Brüstlein.

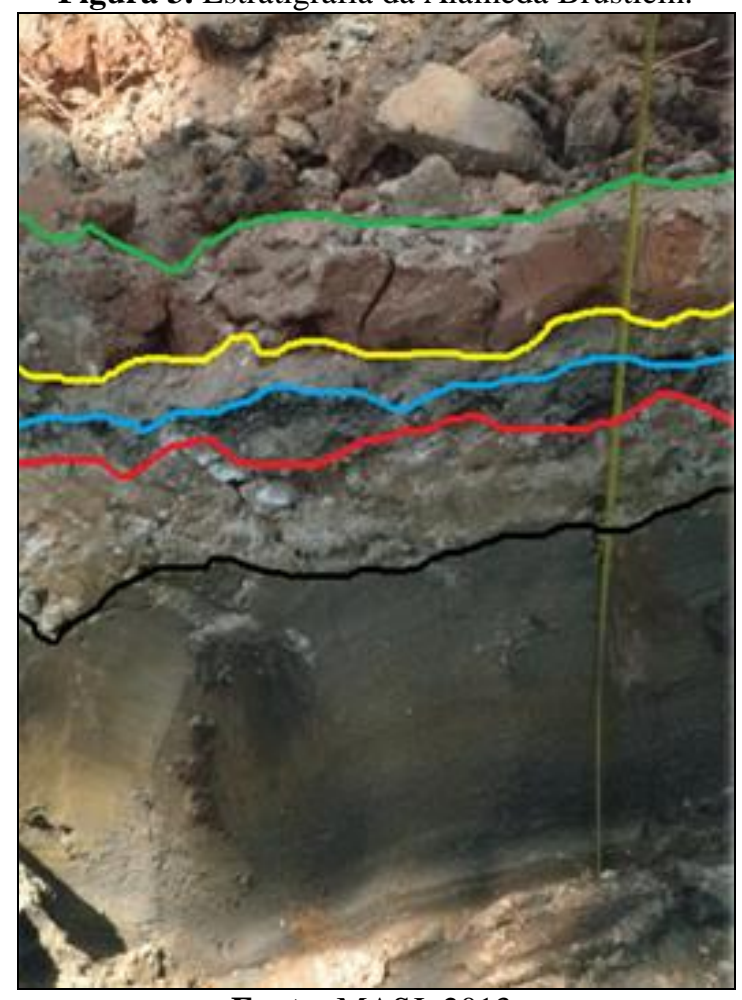

Fonte: MASJ, 2013.

Em 1896, a Alameda já contava com suas palmeiras imperiais, que ajardinavam o caminho de entrada a casa da administração da colônia (Figura 4). 
Figura 4. Alameda Brüstlein em 1896.

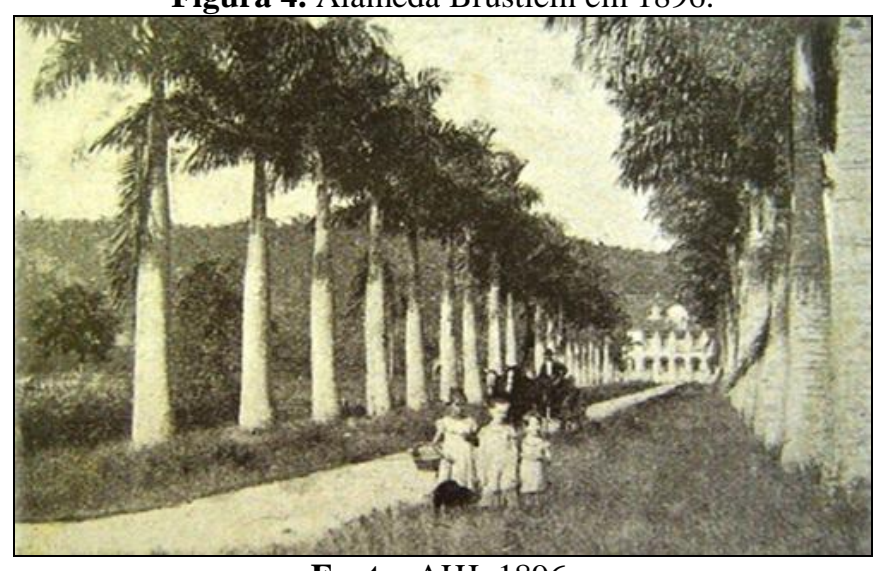

Fonte: AHJ, 1896.

Em 1905, a Alameda Brüstlein conta com as primeiras casas no seu entorno e recebe algumas melhorias no caminho inicial a partir do primeiro aterramento, conforme demonstra a Figura 5:

Figura 5. Alameda Brüstlein em 1905.

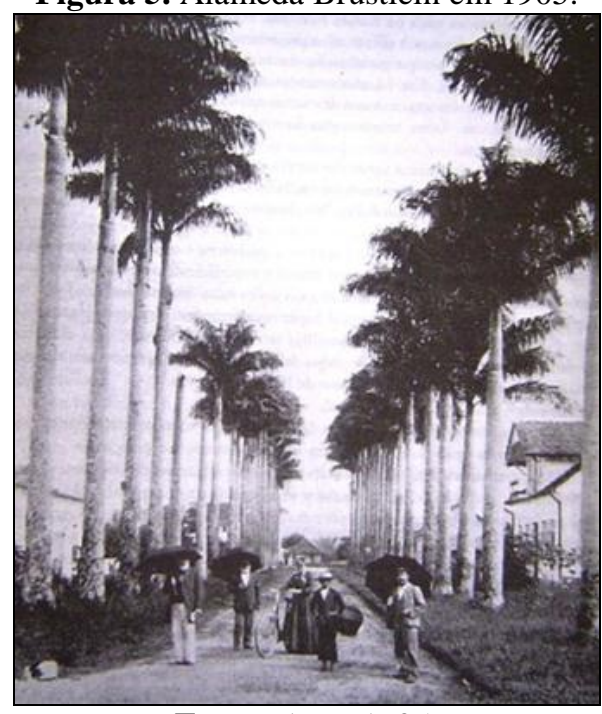

Fonte: AHJ, 1905.

Em 1929, tem-se outra camada de aterro como preparação para o recebimento de uma fina camada de cobertura asfáltica (Figura 6). Esta via, segundo informação fornecida pelo morador Fischer (2012), recebeu inicialmente paralelepípedo e depois asfalto, sendo uma das primeiras em Joinville a ter este tipo de pavimentação. Durante muitos anos, a Alameda foi via de acesso direto ao museu - por meio de carroça, carros, bicicleta ou a pé - onde a população apreciava o local e suas palmeiras. 
Figura 6. Alameda Brüstlein em 1929.

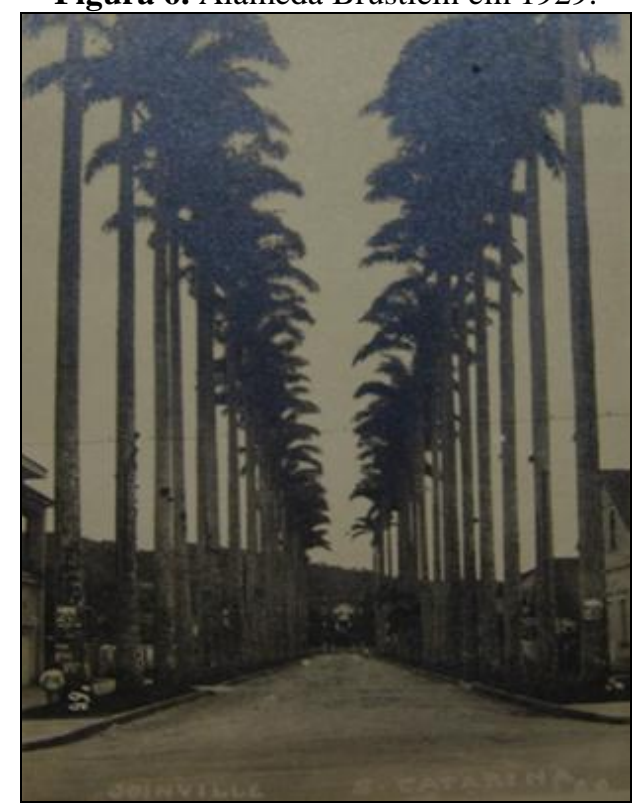

Fonte: AHJ, 1929.

Em 1950, novamente tem-se outro aterramento com uma fina camada de areia para receber a pavimentação com paralelepípedo (Figura 7). Durante a pesquisa arqueológica que procedeu uma intervenção em frente à casa n. 82, foi verificado que havia calçamento de paralelepípedos e, na outra intervenção, na lateral da Farmácia Minâncora, havia calçada de cimento. Abaixo dos calçamentos em todos os trechos escavados haviam aterros identificados por camadas de sedimentos diferenciados sobrepostos. Foram identificadas camadas constituídas de areia (base para os paralelepípedos), de brita e de saibro (de granulometria, textura e coloração variada).

Figura 7. Alameda Brüstlein em 1950.

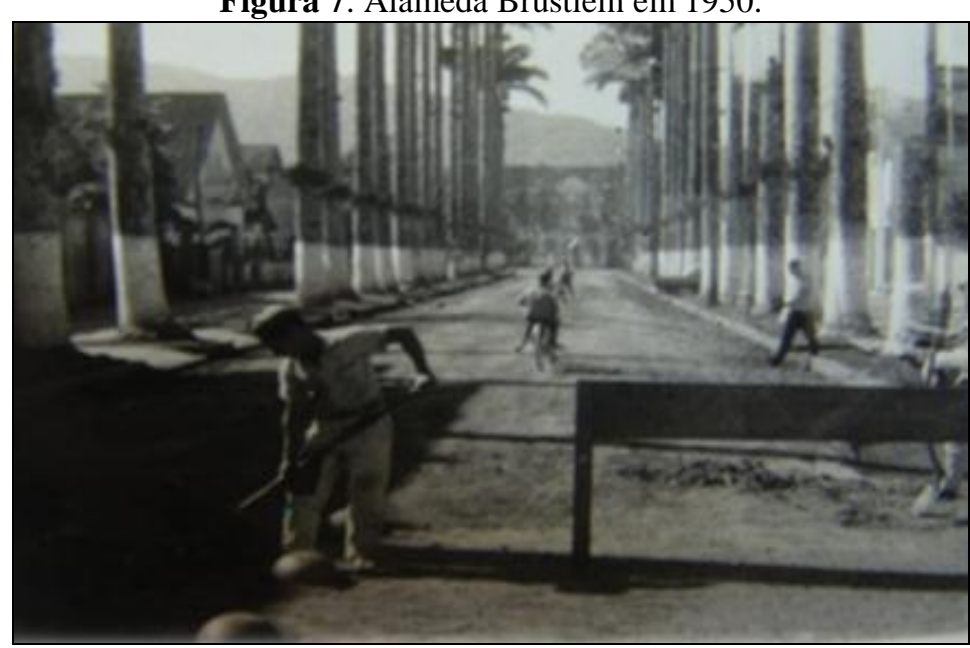

Fonte: AHJ, 1950. 
No início da década de 1970, a Alameda Brüstlein recebeu a maior camada de aterro, quando sob o título de Boulevard, sua paisagem foi modificada possibilitando apenas o tráfego de pedestres, ficando o acesso de carros possível apenas em suas laterais (Figura 8). O Boulevard foi pensado no intuito de estabelecer um espaço público de convivência e foi projetado pelo artista Joinville Juarez Machado.

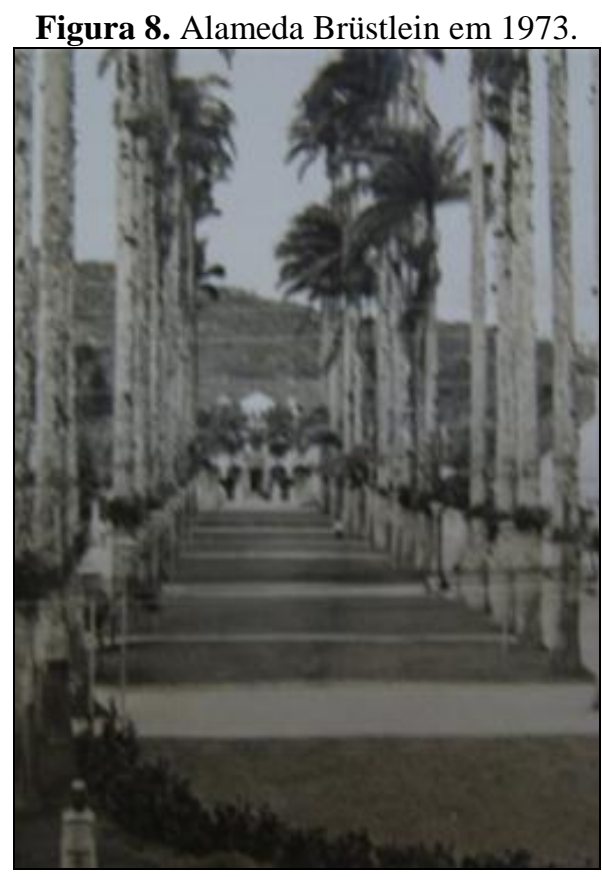

Fonte: AHJ, 1973.

Nessa época, Joinville receberia o segundo momento de grande migração de pessoas. Com o crescimento industrial registrado no período e com um parque fabril diversificado, o município começa a atrair mão-de-obra de outros municípios de Santa Catarina e também de fora do estado, principalmente dos estados do Paraná e São Paulo. Muito provavelmente, a modificação do espaço foi pensando nesse momento como uma transformação da cidade ou talvez como uma forma de delimitar o espaço urbano no centro da cidade.

Por último, tem-se a transformação do espaço a partir do processo de readequação da Alameda Brüstlein, em 2012, quando foi retomado o percurso original, num caminho sinuoso. Novamente o espaço foi moldado pensando no lugar para a integração das pessoas, mas também como forma de delimitar o espaço urbano, ressignificando o território, privilegiando certos grupos e excluindo outros, pois a cidade é um espaço em transformação, que abriga uma multiplicidade de grupos. Tendo 
o tecido urbano como um espaço multifacetado que comporta espaços e pessoas, mas também abriga olhares, necessidade e intensões, que se estabelecem nos vários territórios sobrepostos nesse espaço, entende-se a Alameda Brüstlein como um fator aglutinador de memórias que ao longo dos anos e das transformações vivenciadas reforçou identidades e contribuindo para sua manutenção.

As transformações que ocorreram na Alameda Brüstlein, por hora também pudessem revelar questões ideológicas, preferências políticas de alguns grupos na colônia, no entanto, mais do que uma mudança física na paisagem, a transformação calcada na condição simbólica redefine o espaço construído, que adquiri novos significados gerando nova materialidade.

\section{REFERÊNCIAS}

FICKER, C. História de Joinville: crônica da Colônia Dona Francisca. Joinville: Letra Dágua, 2008.

FISCHER, G. R. Revitalização da Rua das Palmeiras [abr. 2012]. Entrevistadora: Valéria Konig Esteves. Joinville: Coordenação de Patrimônio Cultural de Joinville, 2012.

FUNARI, P. P. Historical archaeology from a world perspective. In: Historical archaeology: back from the edge. Londres: Routledge, 1999, p. 37-66.

GUEDES, S. P. L. de C. A colônia Dona Francisca: a vida... o medo... a morte. In: . et al. História de (I)migrantes: o cotidiano de uma cidade. Joinville: UNIVILLE, 2005.

HILLS, C. Arqueología histórica y textual. In: RENFREW, C.; BAHN, P. Arqueología: conceptos clave. Madri: Akal, 2008. p. 100-105.

INGOLD, T. The perception of the environment: essays in livelihood, dwelling and skill. London: Routledge, 2000.

JOINVILLE. Decreto n. 12.276, de 09 de março de 2005. Disponível em: $<$ https://www.joinville.sc.gov.br/arquivo/download/codigo/150-

Jornal\%2Bdo\%2Bmunic\%C3\%ADpio\%2B571.html>. Acesso em: 20 jan. 2015.

LINKE, V. Paisagem dos sítios de arte rupestre da região de Diamantina. 2008. 186 f. Dissertação (Mestrado) - Curso de Geografia, UFMG, Belo Horizonte, 2008.

LOURENÇO, S. R.. Considerações Antropológicas - Contextos cultural e histórico da Colônia Dona Francisca e do município de Joinville: os sentidos e os significados do patrimônio cultural da cidade. Laudo Pericial. Processo Administrativo de 
Tombamento ao imóvel da Alameda Brüstlein, 82. Joinville: Coordenação de Patrimônio Cultural de Joinville, 2011.

MENEZES, U. B. Arqueologia de Salvamento no Brasil: Uma Avaliação Crítica. Seminário sobre Salvamento Arqueológico, Rio de Janeiro, SPHAN, 1988.

ORSER, C. E. Introdução à arqueologia histórica. Belo Horizonte: Oficina dos Livros, 1992.

RODOWICZ-OSWIECIMSKY, T. A Colônia Dona Francisca no sul do Brasil. Florianópolis: UFSC, 1992.

RONAI, M. Paysages. Hérodote, n. 1, p. 125-159, 1976.

SCHIER, R. A. Trajetórias do conceito de paisagem na Geografia. R. RA'E GA, n. 7, Curitiba: UFPR, 2003. p. 79-85.

SILVA, F. C. T. da. História das paisagens. In: CARDOSO, C. F.; VAINFAS, R. Domínios da História: ensaios de teoria e metodologia. Rio de Janeiro: Campus, 1997, p. 203-215.

UNIVERSIDADE FEDERAL DO RIO DE JANEIRO. Informações Básicas das Regiões Metropolitanas. Região Metropolitana do Norte-Nordeste Catarinense. Disponível em: <http://www.observatoriodasmetropoles.ufrj.br/metrodata/ibrm/ibrm_nnecat.htm>. Acesso em: 05 abr. 2014.

VILLAESCUSA, R. G. Una disciplina denominada arqueología del paisage. Apuntes de ciência y tecnologia, Espanha: 2006. p. 28-36.

YUSTOS, P. G. Las dimensiones del paisaje en arqueología. Revista Munibe Antropologia - Arkeologia, San Sebastian, n. 61, p. 139-151, 2010. 